
\title{
25 Research Soure \\ Outcomes of Afatinib in Non-small Cell Lung Cancer Patients Harboring Uncommon Epidermal Growth Factor Receptor Mutations
}

\section{Kewei Zhao}

Qindao University Medical College Affiliated Yantai Yuhuangding Hospital

Shanliang $\mathrm{Hu}$

Qindao University Medical College Affiliated Yantai Yuhuangding Hospital

\section{Wei Dong}

Qindao University Medical College Affiliated Yantai Yuhuangding Hospital

Wei Chen

Qindao University Medical College Affiliated Yantai Yuhuangding Hospital

\section{Yipeng Song}

Qindao University Medical College Affiliated Yantai Yuhuangding Hospital chunsheng wang ( $\sim$ wangcs1990@hotmail.com)

Qindao University Medical College Affiliated Yantai Yuhuangding Hospital https://orcid.org/00000003-4258-1790

\section{Research article}

Keywords: afatinib, uncommon mutations, EGFR, NSCLC

Posted Date: September 17th, 2020

DOl: https://doi.org/10.21203/rs.3.rs-67709/v1

License: (9) This work is licensed under a Creative Commons Attribution 4.0 International License. Read Full License 


\section{Abstract}

Background: Uncommon epidermal growth factor receptor (EGFR) mutations are a heterogeneous population of molecular alterations, and clinical data on the outcomes of afatinib in patients with nonsmall cell lung cancer (NSCLC) harboring uncommon EGFR mutations are limited. The purpose of this pooled analysis was to investigate the clinicopathological features of uncommon EGFR mutations in patients and the treatment response and survival associated with afatinib treatment.

Methods: We performed a literature search in the NCBI PubMed database to identify relevant articles and completed a pooled analysis based on 37 related published studies.

The relationship between clinical characteristics, EGFR mutation type and treatment response were analyzed using univariate chi-square analysis, and survival analysis was performed using the KaplanMeier method.

Results: A total of 57 patients were included in this pooled analysis. The objective response rate to treatment with afatinib was $46.4 \%$, with a median PFS of 7.0 months.

Patients with a single uncommon EGFR mutation are more likely than patients with multiple mutations to show a good tumor response after receiving afatinib (ORR: $57.9 \%$ vs $26.3 \%$, HR: $0.260,95 \%$ Cl: $0.078-$ $0.869, p=0.029)$. Similarly, patients with a single uncommon EGFR mutation had a longer PFS than patients with multiple mutations (mPFS: 10.0 months vs 3.6 months, HR: $2.906,95 \%$ Cl: $1.496-5.646$, $p=0.002$ ). In addition, for patients with a good treatment response, the PFS was also longer (HR: 2.902, 95\% Cl: 1.522-5.533, p=0.001).

Conclusions: For patients with uncommon mutations, the outcomes of afatinib is worse than that of patients with classic sensitive mutations but higher than that of EGFR wild-type patients. Uncommon EGFR mutations contain various subtypes, and different subtypes have different sensitivities to afatinib. Patients with a single rare mutation show better treatment responses to afatinib and better prognoses than patients with multiple mutations.

\section{Introduction}

Epidermal growth factor receptor (EGFR) mutations play an important role in the pathogenesis of nonsmall cell lung cancer (NSCLC) and are one of the main driver genes of NSCLC. The frequency of EGFR mutations among Caucasians is $10 \%-20 \%$, while the incidence in Asian NSCLC patients is as high as $30 \%-60 \%[1-3]$. In NSCLC patients with EGFR gene mutations, the most common mutation is exon 19 deletions (19del), followed by point mutations L858R in exon 21[3]. Both mutations are considered to be classic mutations of EGFR and sensitive mutations, accounting for $80-90 \%$ of mutations in the EGFR gene[3-5]. A number of clinical studies[6-12] have confirmed that, compared with traditional chemotherapy, EGFR-tyrosine kinase inhibitors (EGFR-TKIs) targeting EGFR mutations have an objective response rate (ORR) as high as $70 \%-80 \%$, a median progression-free survival (mPFS) ranging from 9.6 
months to 18.9 months, and an overall survival (OS) ranging from 21.6 months to 34.1 months; thus, EGFR-TKIs have become the first-line standard treatment for EGFR-sensitive mutations in NSCLC. In addition to the two most common types of EGFR mutations mentioned above, other types of EGFR mutations were also found in the region between exons 18-21 of the EGFR gene, called uncommon or nonclassical mutations, accounting for approximately $10-15 \%$ of EGFR mutations[13-15]. Since uncommon mutations in EGFR are relatively insensitive to the treatment of EGFR-TKIs, which may have a negative impact on research results, most clinical trials investigating the efficacy of EGFR-TKIs do not include patients with uncommon mutations[13-16]. Only a post hoc analysis of the LUX-Lung series trials evaluated the activity of EGFR-TKIs in NSCLC patients with uncommon mutations $[14,15]$. Due to the small sample size and high heterogeneity of patients with uncommon EGFR mutations, the efficacy of EGFR-TKIs for patients with rare EGFR mutations is still unclear. With the rapid development of genetic

testing technology, the detection rate of uncommon EGFR mutations will continue to increase, and it is of great significance to better understand the sensitivity, tumor response and prognosis of these patients to various TKIs.

It has been reported that afatinib, an irreversible ErbB family blocker, is more effective than firstgeneration TKIs in treating uncommon EGFR mutations[14, 17-19]. However, due to the low frequency of uncommon EGFR mutations and the uncertain outcomes of afatinib, the number of patients receiving afatinib in clinical practice was relatively small. The related reports are mainly small retrospective studies and case reports[17-22]. Therefore, we conducted this pooled analysis to explore the clinical characteristics of patients with uncommon EGFR mutations, as well as the efficacy and outcomes of applying afatinib, to provide a reference for clinicians to formulate treatment plans for patients with rare EGFR mutations.

\section{Methods}

\section{Search Strategy}

We performed a literature search in NCBI PubMed database to identify all the relevant articles without language restriction (the last search update was January 15, 2020). The following search strategy were used: ((afatinib[title/abstract]) and ((EGFR [title/abstract]) or epidermal growth factor receptor[title/abstract])) and ((NSCLC [title/abstract]) or non-small cell lung cancer[title/abstract]). We also manually checked the references lists of all related articles to supplement more research.

\section{Study eligibility and data extraction}

Two authors ( $D$ W and KW Z) independently screened the titles and abstracts of the search results and a second screening of the full-text articles. If these two authors fail to reach a consensus, a third investigator (SL H) was consulted to resolve the disagreements in consultation and reach a consensus on all items. Articles were included if they met the following inclusion criteria: 1) articles focusing on 
patients with non-small cell lung cancer; 2) prospective or retrospective studies, case reports and letters to the editor were all included due to the small number of relevant articles; and 3) all patients harbored uncommon mutations in EGFR and received afatinib targeted therapy in any treatment lines. 4)treatment response to afatinib, also known as complete response (CR), partial response (PR), stable disease (SD) or progressive disease (PD) were reported; 4) PFS were reported. Articles meeting any of the following criteria were excluded: 1) patients harbored a common EGFR mutation (19 del or L858R); 2) patients had received any type of EGFR-TKI treatment in the past. For each eligible study, the following data were extracted: age, gender, ethnicity, smoking history, tumor stage, mutation type, response to afatinib, and PFS.

\section{Statistical analysis}

Fisher's exact or chi-squared tests were used to assess the associations between clinical parameters (i.e., age, gender, ethnicity, smoking history, tumor stage, mutation type) and treatment response. The KaplanMeier method and the log-rank test were used to analyze the association of clinical parameters with PFS, and the associated $95 \%$ Cls were calculated. The analyses were performed with SPSS 22.0 program (SPSS Inc, Chicago, IL, USA), a two-sided p-value less than 0.05 was considered statistical significance.

\section{Results}

\section{Search results}

The flow chart of the study selection process is shown in Figure 1. A total of 629 potentially relevant articles were identified from the PubMed database. After removing duplicate records, 602 records remained. After screening the titles and abstracts, 275 articles were excluded, including 162 nonclinical studies and 113 articles not related to afatinib. The remaining 327 articles were further reviewed by reading the full text. Among them, 292 articles were excluded, including 190 articles that focused on common EGFR mutations and 106 articles that lacked data pertaining to efficacy or PFS. Finally, 31 articles met the inclusion criteria, and another 6 articles were identified by searching the reference lists of the articles whose full texts were evaluated. Overall, 37 articles were included in this pooled analysis. They were published between 2015 and 2019 and include 31 case reports and 6 retrospective clinical studies, most of which were conducted in Asia (supplement table 1).

\section{Patient characteristics}

A total of 57 patients were included in the pooled analysis, with a median age of 60 years old, from 34 to 84 years old. Their gender distribution was basically balanced ( 28 males, $49.1 \% ; 29$ females, $50.1 \%$ ), and most of them were Asian patients (34 Asians, 59.6\%; 23 non-Asians, 40.4\%). More than one-third of patients had a history of smoking $(23,40.4 \%)$. Most patients had tumor stage IV $(53,93.0 \%)$. In terms of 
mutation type, two-thirds of patients had a single uncommon EGFR mutation. The baseline characteristics of the patients are detailed in Table 1.

Table 1

Baseline characteristics

\begin{tabular}{|c|c|c|}
\hline Characteristics & No. of patients $(n=57)$ & percentage \\
\hline \multicolumn{3}{|l|}{ Age } \\
\hline median (range) & 60 & $34-84$ \\
\hline \multicolumn{3}{|l|}{ Gender } \\
\hline Male & 28 & 49.1 \\
\hline Female & 29 & 50.9 \\
\hline \multicolumn{3}{|l|}{ Ethnicity } \\
\hline Asian & 34 & 59.6 \\
\hline Non-Asian & 23 & 40.4 \\
\hline \multicolumn{3}{|l|}{ Smoking } \\
\hline Yes & 23 & 40.4 \\
\hline No & 34 & 59.6 \\
\hline \multicolumn{3}{|l|}{ Stage } \\
\hline$|-| I I$ & 4 & 7.0 \\
\hline$\nabla$ & 53 & 93.0 \\
\hline \multicolumn{3}{|l|}{ Mutation type } \\
\hline Single & 38 & 66.7 \\
\hline Multiple & 19 & 33.3 \\
\hline \multicolumn{3}{|l|}{ Response to TKI } \\
\hline CR & 1 & 1.8 \\
\hline PR & 26 & 45.6 \\
\hline SD & 16 & 28.1 \\
\hline PD & 14 & 24.6 \\
\hline
\end{tabular}


In these 57 patients, there were 31 types of uncommon EGFR mutations. As shown in Figure 2a, the top six EGFR mutation types were 20 ins, S768I, 19 del + T790M, 18 del, 19 ins and L747P, with 7 cases (12.3\%), 6 cases (10.5\%), 5 cases (8.8\%), 3 cases (5.3\%), 3 cases (5.3\%), and 3 cases $5.3 \%$, respectively. For every single mutation site, these 57 patients harbored a total of 80 EGFR mutation sites, including eight 21 exon L858R mutations, five 19 exon deletions, and 67 uncommon EGFR mutation sites. As shown in Figure 2b, in addition to L858R, 19del and T790M, the uncommon mutations with higher mutation frequencies are S768I, 20 ins, 18 del, 19 ins, C797S, G719S, G719X, L747P, L833V, and L861Q, accounting for $11.3 \%, 8.8 \%, 3.8 \%, 3.8 \%, 3.8 \%, 3.8 \%, 3.8 \%, 3.8 \%, 3.8 \%, 3.8 \%, 3.8 \%$, and $3.8 \%$ of mutations, respectively.

\section{Clinical outcomes}

Regarding the efficacy of afatinib treatment, of the 57 patients, 1 patient had a complete response (1.8\%), 26 patients had a partial response (45.6\%), 16 patients had stable disease (28.1\%), and 14 patients had disease progression (24.6\%) (Table 1). Overall, the objective response rate to treatment with afatinib was 47.4\% (Table 2). Fisher's exact and chi-squared tests show that the number of EGFR mutations is related to the treatment response to afatinib. Patients with a single uncommon EGFR mutation are more likely to show a good tumor response after receiving afatinib than patients with multiple mutations (ORR:57.9\% vs $26.3 \% \otimes H R: 0.260,95 \% \mathrm{Cl}: 0.078-0.869, \mathrm{p}=0.029)$. However, age (HR:2.512,95\%Cl:0.863-7.310, $\mathrm{p}=0.091)$, gender (HR:0.612,95\%Cl:0.2115-1.744, $p=0.358$ ), gender (HR:0.612,95\% $\mathrm{Cl}: 0.2115-1.744, p=0.358$ ), ethnicity (HR:0.571,95\%Cl:0.195-1.675, p=0.307), smoking history (HR:0.970,95\%Cl:0.336-2.798, $\mathrm{p}=0.955)$, and tumor stage (HR:1.120,95\% Cl:0.078-8.552, $\mathrm{p}=0.913$ ) were not correlated with efficacy (Figure 3).

The median PFS was 7.0 months (Table 2). As shown in Figure 4a, the Kaplan-Meier curves for PFS revealed that patients with a single uncommon EGFR mutation had a longer PFS than patients with multiple mutations (HR:2.906,95\%Cl:1.496-5.646, $\mathrm{p}=0.002$ ). In addition, for patients with a good treatment response, the PFS was also longer (HR: 2.902, 95\% Cl: 1.522-5.533, $p=0.001$ ) (Figure $4 b$ ). However, age (HR: 0.872, 95\% Cl: 0.471-1.617, p=0.664), gender (HR: 1.072, 95\% Cl: 0.580-1.984, $\mathrm{p}=0.824$ ), ethnicity (HR: $1.375,95 \% \mathrm{Cl}: 0.733-1.440, p=0.321$ ), smoking history (HR: $0.757,95 \% \mathrm{Cl}$ : $0.398-$ $1.440, p=0.397$ ), and tumor stage (HR: $0.296,95 \% \mathrm{Cl}: 0.041-2.160, p=0.230)$ were not correlated with efficacy. (Figure 5).

\section{Subgroup analysis}

Based on the number of EGFR mutation sites, we conducted further analysis of treatment response and survival. A total of 38 patients harbored a single mutation. After treatment with afatinib, a total of 22 patients showed treatment response, with an objective response rate of $57.9 \%$ and a median PFS of 10.0 months. Further analysis revealed that the number of patients with mutations in exon 18, exon 19, exon 20, and exon 21 was 10, 10, 13, and 5, respectively; these patients had objective response rates of $70.0 \%$, 
$60.0 \%, 46.2 \%$, and $60.0 \%$, respectively; and they had a median PFS of 11.0, 12.0, 7.4 and 10.9 months, respectively. For a single uncommon EGFR mutation, patients with mutations in exon 20 and exon 21 had poorer tumor responses and prognoses. In contrast, patients whose mutation sites were located on exon 18 and exon 19 had a better ORR and mPFS than the average value. For patients with multiple mutations, the ORR and mPFS were worse than among patients with a single mutation (ORR: $26.3 \%$ vs $57.9 \%$, mPFS: 3.6 months vs 10.0 months, respectively). The ORR and PFS of patients with multiple mutations containing common mutations were the worst, at only $23.1 \%$ and 2.2 months, respectively (Table 2 ).

Table 2

Outcomes of different singel mutation location and different double mutation pattrens

\begin{tabular}{|lllll|}
\hline Categories & No. of patients & OR & ORR & mPFS \\
\hline Singel mutation & 38 & 22 & $57.9 \%$ & 10.0 \\
\hline Exon 18 & 10 & 7 & $70.0 \%$ & 11.0 \\
Exon 19 & 10 & 6 & $60.0 \%$ & 12.0 \\
\hline Exon 20 & 13 & 6 & $46.2 \%$ & 7.4 \\
\hline Exon 21 & 5 & 3 & $60.0 \%$ & 10.9 \\
\hline Double mutation & 19 & 5 & $26.3 \%$ & 3.6 \\
\hline Common + & 13 & 3 & $23.1 \%$ & 2.2 \\
\hline Common - & 6 & 2 & $33.3 \%$ & 3.6 \\
\hline All & 57 & 27 & $47.4 \%$ & 7.0 \\
\hline
\end{tabular}

\section{Discussion}

In this study, the clinicopathological characteristics of 57 NSCLC patients with rare EGFR mutations and their correlation with the efficacy of afatinib were analyzed. We found that the ORR of patients with rare EGFR mutations was $46.4 \%$, and the median PFS was 7.0 months when treated with afatinib. Patients with a single rare mutation were superior to patients with multiple mutations in both tumor response and prognosis. However, patients with uncommon EGFR mutations have a lower ORR and PFS than patients with classic mutations but a higher ORR and PFS than EGFR wild-type patients.

In this study, a total of 38 patients had a single rare mutation. The ORR among these patients was $57.9 \%$, and the median PFS was 10.0 months after afatinib treatment, both lower than among patients with classical mutations, who had an ORR and mPFS of $70 \%$ and 11.9 months, respectively[10, 23], but higher than that among patients with wild-type EGFR[24]. Among the patients with a single rare mutation, 10 patients had 18 exon mutations, and their ORR and mPFS were $70.0 \%$ and 11.0 months, respectively. The ORR was the highest in patients with single mutations on different exons, and the median PFS among these patients is second only to patients with a mutation in exon 19, which is 12 months. According to 
reports, the mutation rate in exon 18 is $3.2 \%-4 \%[25,26]$. In this study, the G719X point mutation was the most common type of exon 18 mutation, which is consistent with previous studies[27]. According to reports, the G719X point mutation accounts for approximately $3.10 \%$ of the total EGFR mutations and $20 \%$ of the rare EGFR mutations $[27,28]$. An analysis of a multicenter study showed that patients with G719X point mutations received first-generation EGFR-TKI treatment, the disease control rate (DCR) was $66.7 \%$, and the mPFS was 8.38 months[29]. Compared with the first generation of EGFR-TKIs, the EGFR G719X point mutation seems to be more sensitive to afatinib[14, 30,31]. The ORR of afatinib in the treatment of NSCLC patients with the G719X mutation was $75 \%-77.8 \%$, the mPFS was $12.1-13.8$ months, and the mOS was 26.9. Among all the exon 18 deletion mutations, the delE790_T710insD mutation is another common mutation type, accounting for approximately $0.30 \%$ of the total EGFR mutations[28]. A case report showed that after two months of treatment with afatinib in a patient with a mutation, imaging showed that the lesion was significantly reduced[32]. An et al[33] reported that after 3 months of treatment with afatinib, brain metastasis was significantly reduced, reached PR, and was maintained for 11 months in a Chinese patient with the delE790_T710insD mutation. This suggests that patients with the delE790_T710insD mutation may be sensitive to afatinib. However, because of the low mutation rate of $18 \mathrm{del}$ and the limited number of research cases, further clinical research and follow-up are needed to confirm this conclusion. Uncommon mutations in exon 19 are characterized by insertion mutations and point mutations. Exon 19 insertion mutations are rare even in uncommon mutations, accounting for approximately $0.2 \%$ of all EGFR mutations. In vitro experiments show that the insertion mutation of exon 19 is sensitive to afatinib[34], and there are also clinical reports that prove this view, indicating that the mutation is sensitive to afatinib[35,36]. Other uncommon mutation types in exon 19 are reported less, and their sensitivity to different EGFR-TKIs is also different. In this study, the ORR in patients with uncommon mutations in exon 19 was $60.0 \%$ with an mPFS at 12 months, which was the longest among the different subgroups. The uncommon mutations in exon 20 mainly show insertion mutations and point mutations. Mutations in exon 20 are often associated with low ORR and PFS. In this study, the ORR of patients with mutations in exon 20 was only $46.3 \%$, and the mPFS was only 7.4 months, which was significantly lower than the overall level. The exon 20 insertion mutation is the most common type of mutation in rare EGFR mutations, accounting for approximately $30 \%$ of rare EGFR mutations and 4.8\%-12\% of all EGFR mutations[37]. Yang et al.[14] reported 23 cases of 20 exon insertion mutations treated with afatinib; the ORR was $8.7 \%$, DCR was $65.2 \%$, and mPFS was 2.7 months, indicating that the exon 20 insertion mutation is resistant to afatinib. The point mutation of exon 20 is mainly S768I, accounting for approximately $1.1 \%$ of the total EGFR mutations. In vitro experiments indicate that the S768I mutation is more sensitive to afatinib than first- and third-generation TKIs [38], and clinical research results also support this view. In the analysis of the LUX-Lung 2, LUX-Lung 3 and LUX-Lung 6 trials, the patients with the $\mathrm{S} 768 \mathrm{I}$ mutation who received afatinib had an ORR of $100 \%$ and a median PFS of 14.7 months[14]. Therefore, patients with $\mathrm{S768I}$ mutations will benefit more from afatinib treatment but should also pay attention to individual sensitivity differences. The uncommon mutation of exon 21 is mainly the point mutation L861Q. Yang et al.[14] found that the ORR of patients with the L861Q mutation treated with afatinib was $56.3 \%$, PFS was 8.2 months, and OS was 17.1 months. It can be seen that the efficacy of afatinib in the treatment of patients with the L861Q mutation is better than that of first- 
generation TKIs, which is similar to the 18 exon G719X mutation and the 20 exon S861I mutation, but its sensitivity is lower than G719X (ORR: 77.8\%, PFS: 13.8 months) and S768I (ORR: 100\% PFS: 14.7 months), which suggests that the L861Q mutation may be a rare type of mutation with strong heterogeneity.

In addition to a single mutation, two or more different types of EGFR mutations may coexist in tumor cells at the same time, known as multiple mutations. EGFR multiple mutations can be roughly divided into three categories: double classical mutations, nonclassical mutations coexist with classical mutations, and different nonclassical mutations coexist. In this study, it was found that the tumor response and prognosis of patients with multiple mutations were worse than those with single mutations, with an ORR of $26.3 \%$ and an mPFS of 3.6 months. Among them, patients harboring multiple mutations with classic mutations had the worst outcomes, with an ORR of only $23.1 \%$ and an mPFS of only 2.2 months. This may be because most of these patients carry the T790M mutation, which is considered to be a drug-resistant mutation treated by EGFR-KTIs. Previous studies have shown that multiple mutations that coexist with classic mutations and other nonclassical mutations are more sensitive to EGFR-TKIs than those mutations that coexist with classic mutations and T790M mutations. The sensitivity of double classical mutations to TKIs is the best of all multiple mutations[39]. This suggests that the efficacy of EGFR multiple mutations on TKIs may be affected by the sensitivity of the accompanying mutations to TKIs and that different subtypes of mutations respond differently to TKIs, which requires further clinical studies to verify.

We acknowledge that our research has some limitations. First, this is a pooled analysis of the published literature that includes mostly case reports, and there may be some potential confounding factors beyond our control, such as publication bias, choice bias and residual confusion of unmeasured factors that cannot be ruled out. Second, the sample size of this study is relatively small, which may affect the accuracy of the results, and a large randomized controlled study is needed to verify our conclusions. Third, the genetic testing of the samples and methods adopted by patients may be different, which may affect the ability to detect gene mutations and the consistency of the results.

\section{Conclusion}

In summary, as a special type of EGFR mutation, uncommon EGFR mutations contain various subtypes, and different subtypes have different sensitivities to afatinib. In this study, patients with uncommon mutations who received afatinib had an ORR of $46.4 \%$ and mPFS of 7.0 months, which was lower than among patients with classic sensitivity mutation but higher than among EGFR wild-type patients. Patients with a single rare mutation show better treatment responses to afatinib and better prognoses than patients with multiple mutations.

\section{Declarations}

\section{Ethics approval and consent to participate}


The ethics committee of Yantai Yuhuangding Hospital approved the study. And informed consent was exempted due to the pooled nature of the study.

\section{Consent for publication}

All authors have approved the manuscript and agree with submission to BMC cancer.

\section{Availability of data and materials}

The datasets used and/or analyzed during the current study are available from the corresponding author on reasonable request.

\section{Competing interests}

The authors declare that they have no competing interests.

\section{Funding}

This research is supported by the Yantai Science and Technology Bureau Support Grant/Science and Technology Innovation Development Project(2020MSGY085).

\section{Authors' contributions}

Conceptualization, Chunsheng Wang and Yipeng Song; Methodology, Chunsheng Wang and Yipeng Song; Software, Kewei Zhao and Wei Chen; Formal Analysis, Shanliang Hu; Resources, Wei Dong and Kewei Zhao; Data Curation, Wei Chen; Writing-Original Draft Preparation, Shanliang Hu; Writing-Review \& Editing, Wei Dong; Supervision, Chunsheng Wang and Yipeng Song; Project Administration, Chunsheng Wang and Yipeng Song.

\section{Acknowledgements}

Not applicable

\section{References}

1. Rosell R, Moran T, Queralt C, Porta R, Cardenal F, Camps C, Majem M. Screening for epidermal growth factor receptor mutations in lung cancer. N Engl J Med. 2009;361(10):958-67. 
2. Shi Y, Au JS-K, Thongprasert S, Srinivasan S, Tsai C-M, Khoa MT, Heeroma K, Itoh Y, Cornelio G, Yang P-C. A prospective, molecular epidemiology study of EGFR mutations in Asian patients with advanced non-small-cell lung cancer of adenocarcinoma histology (PIONEER). J Thorac Oncol. 2014;9(2):154-62.

3. D'Angelo SP, Pietanza MC, Johnson ML, Riely GJ, Miller VA, Sima CS, Zakowski MF, Rusch VW, Ladanyi M, Kris MG. Incidence of EGFR exon 19 deletions and L858R in tumor specimens from men and cigarette smokers with lung adenocarcinomas. J Clin Oncol. 2011;29(15):2066-70.

4. Sharma SV, Bell DW, Settleman J, Haber DA. Epidermal growth factor receptor mutations in lung cancer. Nat Rev Cancer. 2007;7(3):169-81.

5. Lynch TJ, Bell DW, Sordella R, Gurubhagavatula S, Okimoto RA, Brannigan BW. Activating mutations in the epidermal growth factor receptor underlying responsiveness of non-small-cell lung cancer to gefitinib. N Engl J Med. 2004;350(21):2129-39.

6. Yang JC, Wu YL, Chan V, Kurnianda J, Nakagawa K, Saijo N, Fukuoka M, McWalter G, McCormack R, Mok TS. Epidermal growth factor receptor mutation analysis in previously unanalyzed histology samples and cytology samples from the phase III Iressa Pan-ASia Study (IPASS). Lung Cancer. 2014;83(2):174-81.

7. Mitsudomi T, Morita S, Yatabe Y, Negoro S, Okamoto I, Tsurutani J, Seto T, Satouchi M, Tada H, Hirashima T, et al. Gefitinib versus cisplatin plus docetaxel in patients with non-small-cell lung cancer harbouring mutations of the epidermal growth factor receptor (WJTOG3405): an open label, randomised phase 3 trial. The Lancet Oncology. 2010;11(2):121-8.

8. Zhou C, Wu Y-L, Chen G, Feng J, Liu X-Q, Wang C, Zhang S, Wang J, Zhou S, Ren S, et al. Erlotinib versus chemotherapy as first-line treatment for patients with advanced EGFR mutation-positive nonsmall-cell lung cancer (OPTIMAL, CTONG-0802): a multicentre, open-label, randomised, phase 3 study. The Lancet Oncology. 2011;12(8):735-42.

9. Wu Y-L, Zhou C, Hu C-P, Feng J, Lu S, Huang Y, Li W, Hou M, Shi JH, Lee KY, et al. Afatinib versus cisplatin plus gemcitabine for first-line treatment of Asian patients with advanced non-small-cell lung cancer harbouring EGFR mutations (LUX-Lung 6): an open-label, randomised phase 3 trial. The Lancet Oncology. 2014;15(2):213-22.

10. Paz-Ares L, Tan EH, O'Byrne K, Zhang L, Hirsh V, Boyer M, Yang JC, Mok T, Lee KH, Lu S, et al. Afatinib versus gefitinib in patients with EGFR mutation-positive advanced non-small-cell lung cancer: overall survival data from the phase Ilb LUX-Lung 7 trial. Ann Oncol. 2017;28(2):270-7.

11. Soria JC, Ohe Y, Vansteenkiste J, Reungwetwattana T, Chewaskulyong B, Lee KH, Dechaphunkul A, Imamura F, Nogami N, Kurata T, et al. Osimertinib in Untreated EGFR-Mutated Advanced Non-SmallCell Lung Cancer. N Engl J Med. 2018;378(2):113-25.

12. Ramalingam SS, Vansteenkiste J, Planchard D, Cho BC, Gray JE, Ohe Y, Zhou C, Reungwetwattana T, Cheng Y, Chewaskulyong B, et al. Overall Survival with Osimertinib in Untreated, EGFR-Mutated Advanced NSCLC. N Engl J Med. 2020;382(1):41-50. 
13. Passaro A, Prelaj A, Bonanno L, Tiseo M, Tuzi A, Proto C, Chiari R, Rocco D, Genova C, Sini C, et al. Activity of EGFR TKIs in Caucasian Patients With NSCLC Harboring Potentially Sensitive Uncommon EGFR Mutations. Clin Lung Cancer. 2019;20(2):e186-94.

14. Yang JCH, Sequist LV, Geater SL, Tsai C-M, Mok TSK, Schuler M, Yamamoto N, Yu C-J, Ou S-HI, Zhou $\mathrm{C}$, et al. Clinical activity of afatinib in patients with advanced non-small-cell lung cancer harbouring uncommon EGFR mutations: a combined post-hoc analysis of LUX-Lung 2, LUX-Lung 3, and LUXLung 6. The Lancet Oncology. 2015;16(7):830-8.

15. Russo A, Franchina T, Ricciardi G, Battaglia A, Picciotto M, Adamo V. Heterogeneous Responses to Epidermal Growth Factor Receptor (EGFR) Tyrosine Kinase Inhibitors (TKIs) in Patients with Uncommon EGFR Mutations: New Insights and Future Perspectives in this Complex Clinical Scenario. Int J Mol Sci 2019, 20(6).

16. Sequist LV, Yang JC, Yamamoto N, O'Byrne K, Hirsh V, Mok T, Geater SL, Orlov S, Tsai CM, Boyer M, et al. Phase III study of afatinib or cisplatin plus pemetrexed in patients with metastatic lung adenocarcinoma with EGFR mutations. J Clin Oncol. 2013;31(27):3327-34.

17. Harrison PT, Vyse S, Huang PH. Rare epidermal growth factor receptor (EGFR) mutations in nonsmall cell lung cancer. Semin Cancer Biol. 2020;61:167-79.

18. Liang SK, Ko JC, Yang JC, Shih JY. Afatinib is effective in the treatment of lung adenocarcinoma with uncommon EGFR p.L747P and p.L747S mutations. Lung Cancer. 2019;133:103-9.

19. Galli G, Corrao G, Imbimbo M, Proto C, Signorelli D, Ganzinelli M, Zilembo N, Vitali M, de Braud F, Garassino MC, et al. Uncommon mutations in epidermal growth factor receptor and response to first and second generation tyrosine kinase inhibitors: A case series and literature review. Lung Cancer. 2018;115:135-42.

20. Martin J, Lehmann A, Klauschen F, Hummel M, Lenze D, Grohe C, Tessmer A, Gottschalk J, Schmidt B, Pau HW, et al. Clinical Impact of Rare and Compound Mutations of Epidermal Growth Factor Receptor in Patients With Non-Small-Cell Lung Cancer. Clin Lung Cancer. 2019;20(5):350-62 e354.

21. Masood A, Kancha RK, Subramanian J. Epidermal growth factor receptor (EGFR) tyrosine kinase inhibitors in non-small cell lung cancer harboring uncommon EGFR mutations: Focus on afatinib. Semin Oncol. 2019;46(3):271-83.

22. Wang DD, Lee VH, Zhu G, Zou B, Ma L, Yan H. Selectivity profile of afatinib for EGFR-mutated nonsmall-cell lung cancer. Mol Biosyst. 2016;12(5):1552-63.

23. Park K, Tan E-H, O'Byrne K, Zhang L, Boyer M, Mok T, Hirsh V, Yang JC-H, Lee KH, Lu S, et al. Afatinib versus gefitinib as first-line treatment of patients with EGFR mutation-positive non-small-cell lung cancer (LUX-Lung 7): a phase 2B, open-label, randomised controlled trial. The Lancet Oncology. 2016;17(5):577-89.

24. Ahn MJ, Kim SW, Cho BC, Ahn JS, Lee DH, Sun JM, Massey D, Kim M, Shi Y, Park K. Phase II study of Afatinib as third-line treatment for patients in Korea with stage IIIB/IV non-small cell lung cancer harboring wild-type EGFR. Oncologist. 2014;19(7):702-3. 
25. Kobayashi Y, Togashi Y, Yatabe Y, Mizuuchi H, Jangchul P, Kondo C, Shimoji M, Sato K, Suda K, Tomizawa K, et al. EGFR Exon 18 Mutations in Lung Cancer: Molecular Predictors of Augmented Sensitivity to Afatinib or Neratinib as Compared with First- or Third-Generation TKls. Clin Cancer Res. 2015;21(23):5305-13.

26. Beau-Faller M, Prim N, Ruppert AM, Nanni-Metellus I, Lacave R, Lacroix L, Escande F, Lizard S, Pretet $\mathrm{JL}$, Rouquette I, et al. Rare EGFR exon 18 and exon 20 mutations in non-small-cell lung cancer on 10 117 patients: a multicentre observational study by the French ERMETIC-IFCT network. Ann Oncol. 2014;25(1):126-31.

27. Tu HY, Ke EE, Yang JJ, Sun YL, Yan HH, Zheng MY, Bai XY, Wang Z, Su J, Chen ZH, et al. A comprehensive review of uncommon EGFR mutations in patients with non-small cell lung cancer. Lung Cancer. 2017;114:96-102.

28. Kobayashi Y, Mitsudomi T. Not all epidermal growth factor receptor mutations in lung cancer are created equal: Perspectives for individualized treatment strategy. Cancer Sci. 2016;107(9):1179-86.

29. Pilotto S, Rossi A, Vavala T, Follador A, Tiseo M, Galetta D, Morabito A, Di Maio M, Martelli O, Caffo O, et al. Outcomes of First-Generation EGFR-TKIs Against Non-Small-Cell Lung Cancer Harboring Uncommon EGFR Mutations: A Post Hoc Analysis of the BE-POSITIVE Study. Clin Lung Cancer. 2018;19(1):93-104.

30. Chiu CH, Yang CT, Shih JY, Huang MS, Su WC, Lai RS, Wang CC, Hsiao SH, Lin YC, Ho CL, et al. Epidermal Growth Factor Receptor Tyrosine Kinase Inhibitor Treatment Response in Advanced Lung Adenocarcinomas with G719X/L861Q/S768I Mutations. J Thorac Oncol. 2015;10(5):793-9.

31. Zhang Y, Wang Z, Hao X, Hu X, Wang H, Wang Y, Ying J. Clinical characteristics and response to tyrosine kinase inhibitors of patients with non-small cell lung cancer harboring uncommon epidermal growth factor receptor mutations. Chin J Cancer Res. 2017;29(1):18-24.

32. Ibrahim U, Saqib A, Atallah JP. EGFR exon 18 delE709_T710insD mutated stage IV lung adenocarcinoma with response to afatinib. Lung Cancer. 2017;108:45-7.

33. An N, Wang H, Zhu H, Yan W, Jing W, Kong L, Zhang Y, Yu J. Great efficacy of afatinib on a patient with lung adenocarcinoma harboring uncommon EGFR delE709_T710insD mutations: a case report. Onco Targets Ther. 2019;12:7399-404.

34. He M, Capelletti M, Nafa K, Yun CH, Arcila ME, Miller VA, Ginsberg MS, Zhao B, Kris MG, Eck MJ, et al. EGFR exon 19 insertions: a new family of sensitizing EGFR mutations in lung adenocarcinoma. Clin Cancer Res. 2012;18(6):1790-7.

35. Lin YT, Liu YN, Wu SG, Yang JC, Shih JY. Epidermal Growth Factor Receptor Tyrosine Kinase Inhibitorsensitive Exon 19 Insertion and Exon 20 Insertion in Patients With Advanced Non-Small-cell Lung Cancer. Clin Lung Cancer. 2017;18(3):324-32 e321.

36. Furuya T, Shimada J, Okada S, Tsunezuka H, Kato D, Inoue M. Successful treatment with afatinib for pancreatic metastasis of lung adenocarcinoma: a case report. J Thorac Dis. 2017;9(10):E890-3.

37. Riess JW, Gandara DR, Frampton GM, Madison R, Peled N, Bufill JA, Dy GK, Ou SI, Stephens PJ, McPherson JD, et al. Diverse EGFR Exon 20 Insertions and Co-Occurring Molecular Alterations 
Identified by Comprehensive Genomic Profiling of NSCLC. J Thorac Oncol. 2018;13(10):1560-8.

38. Banno E, Togashi Y, Nakamura Y, Chiba M, Kobayashi Y, Hayashi H, Terashima M, de Velasco MA, Sakai K, Fujita Y, et al. Sensitivities to various epidermal growth factor receptor-tyrosine kinase inhibitors of uncommon epidermal growth factor receptor mutations L861Q and S768I: What is the optimal epidermal growth factor receptor-tyrosine kinase inhibitor? Cancer Sci. 2016;107(8):113440.

39. Xu J, Jin B, Chu T, Dong X, Yang H, Zhang Y, Wu D, Lou Y, Zhang X, Wang H, et al. EGFR tyrosine kinase inhibitor (TKI) in patients with advanced non-small cell lung cancer (NSCLC) harboring uncommon EGFR mutations: A real-world study in China. Lung Cancer. 2016;96:87-92.

\section{Figures}

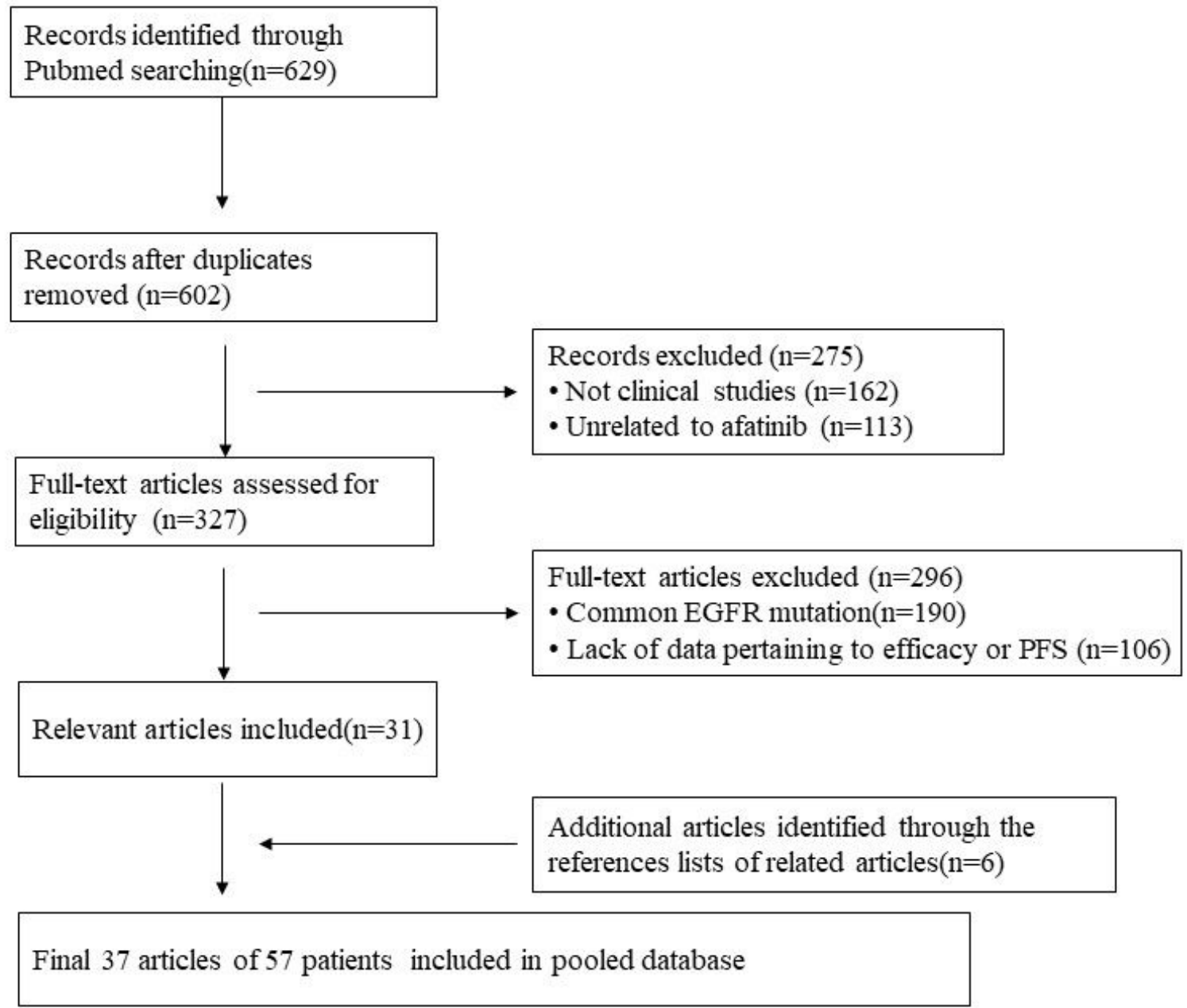

\section{Figure 1}

The flow chart of the study selection process 

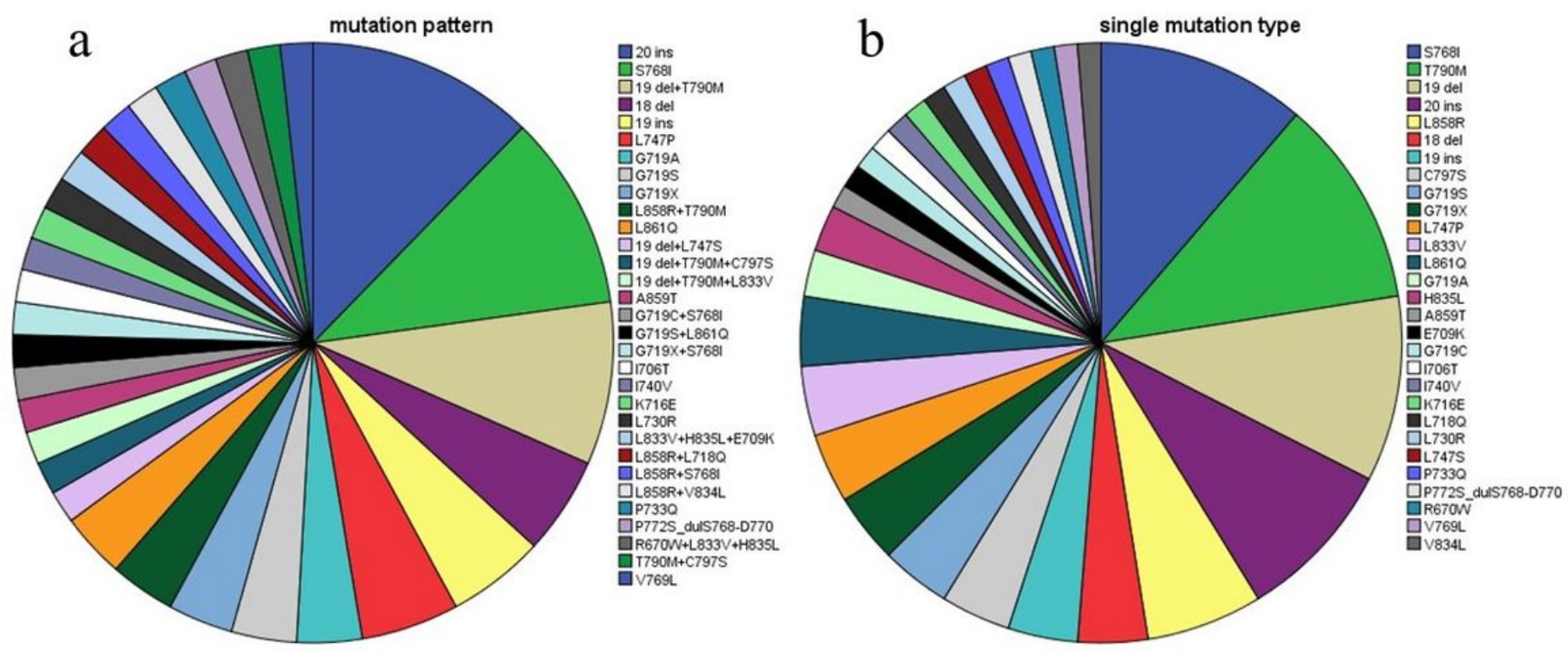

\section{Figure 2}

Mutation types (a) and mutation site(b) analysis

$\begin{array}{lcc}\text { Subgroup } & \text { Reference variable } & \text { Evaluation variable } \\ \text { Age } & \geq 60 & <60 \\ \text { Gender } & \text { Male } & \text { Female } \\ \text { Ethnictity } & \text { Asian } & \text { Non-Asian } \\ \text { Smoking } & \text { Yes } & \text { No } \\ \text { Stage } & \text { III } & \text { IV } \\ \text { Mutation type } & \text { Singel } & \text { Multiple }\end{array}$

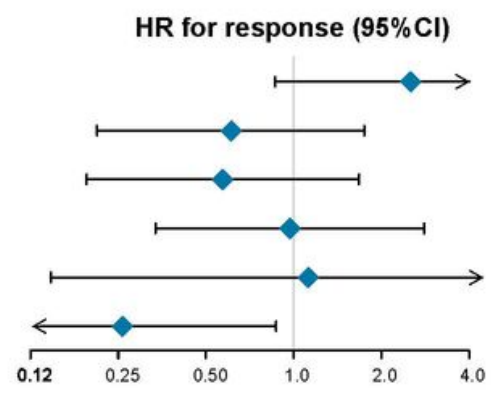

$\begin{array}{cc}\text { HR(95\% CI) } & \text { p } \\ 2.512(0.863-7.310) & 0.091 \\ 0.612(0.2115-1.744) & 0.358 \\ 0.571(0.195-1.675) & 0.307 \\ 0.970(0.336-2.798) & 0.955 \\ 1.120(0.147-8.552) & 0.913 \\ 0.260(0.078-0.869) & 0.029\end{array}$

Figure 3

Subgroup analysis for treatment response 

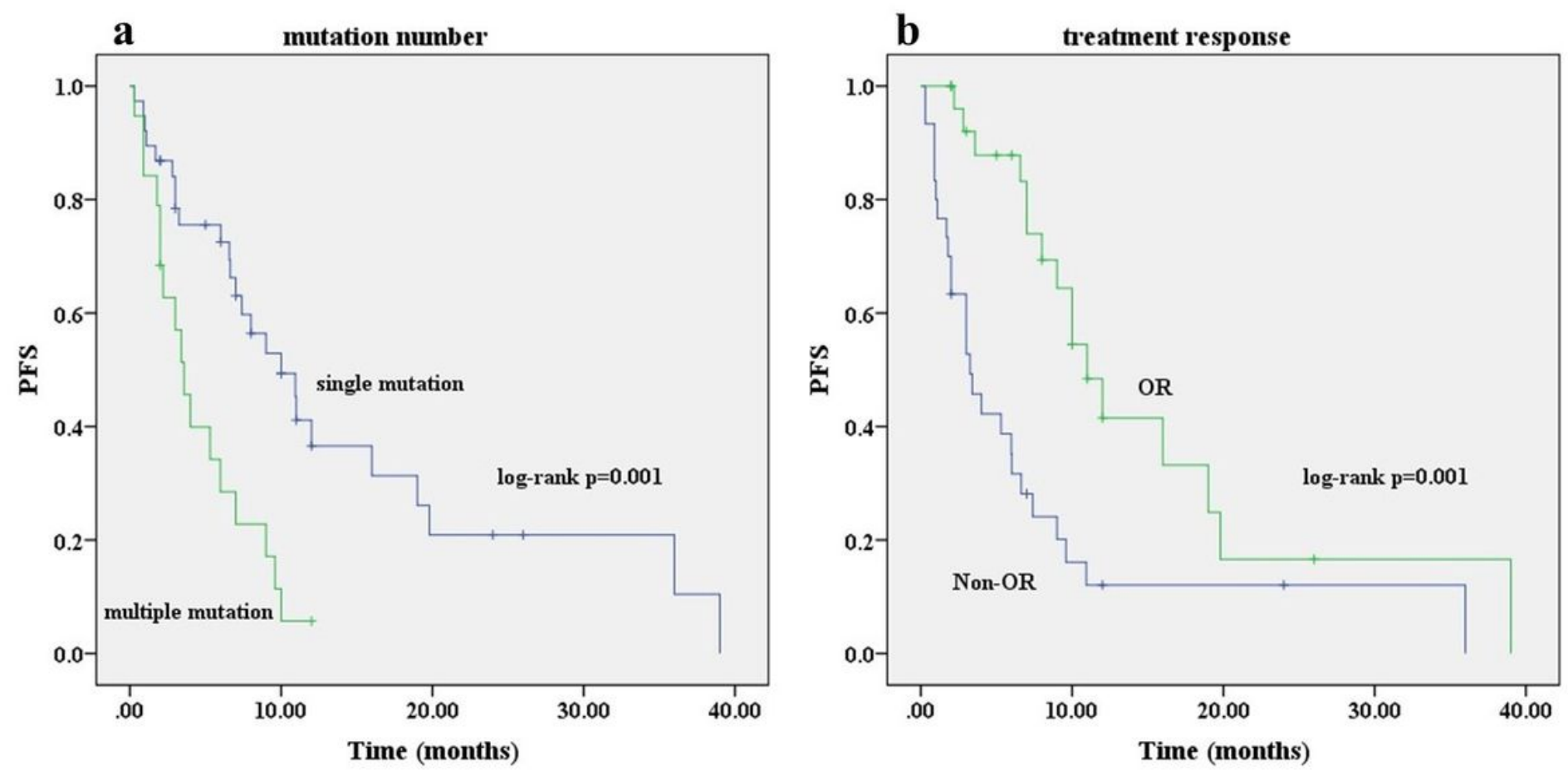

\section{Figure 4}

Survival analysis based on mutation number (a) and treatment response(b)

$\begin{array}{lcc}\text { Subgroup } & \text { Reference variable } & \text { Evaluation variable } \\ \text { Age } & \geq 60 & <60 \\ \text { Gender } & \text { Male } & \text { Female } \\ \text { Ethnictity } & \text { Asian } & \text { Non-Asian } \\ \text { Smoking } & \text { Yes } & \text { No } \\ \text { Stage } & \text { III } & \text { IV } \\ \text { Mutation type } & \text { Singel } & \text { Multiple } \\ \text { TKI response } & \text { OR } & \text { Non-OR }\end{array}$

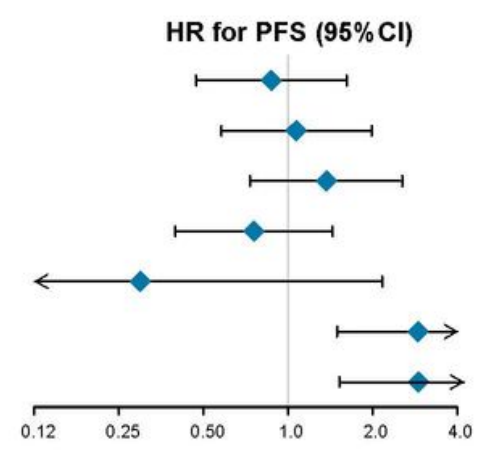

$\begin{array}{cc}\text { HR(95\% Cl) } & \text { p } \\ 0.872(0.471-1.617) & 0.664 \\ 1.072(0.580-1.984) & 0.824 \\ 1.375(0.733-2.577) & 0.321 \\ 0.757(0.398-1.440) & 0.397 \\ 0.296(0.041-2.160) & 0.230 \\ 2.906(1.496-5.646) & 0.002 \\ 2.902(1.522-5.533) & 0.001\end{array}$

Figure 5

Subgroup analysis for PFS

\section{Supplementary Files}

This is a list of supplementary files associated with this preprint. Click to download. 